\title{
A DIMENSÃO CONSTITUINTE DO PODER \\ EM HANNAH ARENDT
}

Odílio Alves Aguiar

RESUMO: O artigo investiga a concepção do poder em Hannah Arendt. O pano de fundo dessa reflexão, na autora, é o mal inerente às práticas de extermínio dos governos totalitários. A nossa exposição ressalta a dimensão constituinte do poder, na qual o poder está associado à capacidade de iniciar e de fundar ações com os outros. Nesse sentido, distancia-se da dimensão constituída do poder: Estado, governo e soberania. Em Arendt, poder diferencia-se de dominação. Os termos que compõem nossa abordagem são: mundo comum, condição humana, ação, espaço público, desobediência civil e potência.

PALAVRAS-CHAVE: Hannah Arendt. Poder. Ação. Espaço público. Desobediência civil.

É consenso, no meio filosófico, que a Filosofia, na versão ocidental, iniciou-se como thaumadzein - espanto ou admiração. A postura de maravilhamento diante da harmonia natural, do que é como é, tem sido uma das principais motivações do filosofar. Essa atitude, porém, não é o ponto de partida da filosofia arendtiana. Concordamos com Eduardo Jardim, quando afirma que a base experiencial do pensamento de Arendt é a dor (cf. JARDIM, 2007, p. 26-28). O trauma causado pelo conhecimento das práticas de genocídio e de extermínio em massa, nos campos de concentração da

*Doutor em Filosofia e Professor da Universidade Federal do Ceará. E_mail: odilio@uol.com.br 
Alemanha, explicita-se na correspondência da autora, a partir de 1943, e passa a refletir em toda a sua obra.

Ao tentar sistematizar a categoria de poder, na autora, nos deparamos irremediavelmente com a experiência totalitária ${ }^{1}$. Isso significa que a reflexão sobre esse tema, em Arendt, não nasce da ruminação erudita das ideias, da defesa de cosmovisões ou de ideologias e, muito menos, do estabelecimento de um novo padrão de poder governamental. A reflexão sobre o poder, nessa trilha, só faz sentido no interior da sua tentativa de compreender e de encontrar os fios dos acontecimentos que não permitem mais o trançado da tradição. Algo aconteceu e não pôde ser explicado com os conceitos tradicionais da filosofia política. Narrar foi o caminho escolhido por Arendt para chegar à compreensão dos acontecimentos provocadores da ruptura totalitária (cf. DISCH, 1994). O totalitarismo, assim, em Arendt, não é uma categoria científica, mas narracional. A experiência totalitária a tornou uma contadora de histórias (storyteller). A narração possibilita verificar que o próprio acontecimento ilumina o que, no passado, pode a ele estar relacionado. O totalitarismo não possui uma história nem está contido potencialmente num evento do passado, mas cristaliza elementos de várias proveniências, a exemplo do imperialismo, do antissemitismo, da crise dos estados nacionais e do eurocentrismo.

A percepção do surgimento de uma nova modalidade de controle e de dominação dos humanos, perpassada pela lógica da violência, da guerra e da morte, foi exposta em Origens do totalitarismo (1951). Essa é a razão de Arendt ter ido muito além de uma visão judaica da experiência totalitária, embora, sem a sua condição de judia, dificilmente teria alcançado a sua peculiar compreensão do fenômeno (cf. BERNSTEIN, 1996). Os campos de concentração colocam em cena o genocídio: naquele momento, um tipo de crime sem nenhuma tipificação nos códigos do direito, na literatura ética ou na Filosofia Política. Leva-se a efeito, pela primeira vez, na história do Ocidente, a instauração de uma forma de governo guiada pela ideia e pela prática do extermínio e, assim, erguida em contraposição ao próprio gênero humano. ${ }^{2}$ O governo totalitário ultrapassa a opressão e a perseguição a um agrupamento humano específico ou a sua expropriação territorial. Não estamos abordando aqui um preconceito social ou religioso, mas um Estado

\footnotetext{
${ }^{1}$ No final da década 1960, em face da atração pela violência no movimento estudantil, político e intelectual, Arendt retoma a reflexão sobre o poder (cf. ARENDT, 1994). Iremos privilegiar, no entanto, a incidência dos campos de concentração pelo peso estrutural e filosófico no pensamento da autora. A importância dos campos de concentração, no pensamento de Arendt, é reconhecida por todos os seus comentadores, mas recebe atenção especial de Agamben (2002), Stanley (1994), Chalier (1989), Chaumont (1992), entre outros.

2 Esse argumento está minuciosamente exposto no texto "Ideologia e terror: uma nova forma de governo". In: ARENDT, 1990, p. 512-531.
} 
que altera a essência mesma da política - e foi justamente isso que os judeus não entenderam. Presos à mentalidade da nação escolhida e da perseguição religiosa, os judeus não perceberam que estavam diante de algo muito diferente e não apenas de proporções maiores. O temor de Arendt, muito bem percebido por Giorgio Agamben ${ }^{3}$, era que essa nova instituição pairasse como um espectro exemplar e se constituísse como parte essencial da vida contemporânea. Arendt é enfática, em Origens do Totalitarismo: estamos diante de uma nova forma de governo que deixa de ser política, baseada na ideia de mundo comum, e passa a se constituir a partir da cesura biológica, do suporte natural e da produção técnico-burocrático-estatal dos "cidadãos" através das organizações, ideologia e polícia secreta.

O surgimento dos campos de concentração como base de sustentação dos governos totalitários fez Arendt ligar o totalitarismo ao mal ${ }^{4}$. Jerome Kohn, assistente de ensino e intérprete de Hannah Arendt, escreveu que o problema do mal é o principal eixo argumentativo a atravessar toda a reflexão político-filosófica arendtiana. Ao ligar essa experiência ao mal, Hannah Arendt apontou o paroxismo da violência perpetrada pelos governos totalitários. O domínio total é mais opressor que a escravidão e a tirania, é mais destruidor que a miséria econômica e o expansionismo territorial. $\mathrm{O}$ controle total atinge e captura burocraticamente os humanos em todas as dimensões das suas vidas; adota, como critério de legitimidade governamental, a redução dos homens a seres naturais. Desse modo, temos uma maneira de compreender a relação do mal com a dominação, nas sociedades secularizadas.

O pano de fundo dessa reflexão, em Arendt, não é a malignidade, a perversão ou o pecado humano. A novidade do seu ponto de vista reside justamente em evidenciar que os seres humanos podem realizar ações inimagináveis sem qualquer motivação maligna. O substrato do exame da questão, em Arendt, é o processo de naturalização da sociedade e de artificialização da natureza ocorrido com a massificação, a industrialização e a tecnificação das decisões e das organizações humanas, na contemporaneidade. O mal é abordado, assim, na perspectiva históricopolítica e não na visão moral ou religiosa.

Podemos captar a relação entre o mal e a dominação em Hannah Arendt, nas obras a seguir: Origens do Totalitarismo (1951), Eichmann em Jerusalém (1963), A Vida do Espírito (1971) e em outros textos publicados postumamente.

3Vale conferir, em especial, o capítulo "O campo como paradigma político moderno". In: AGAMBEN, 2002, p. 125-194

${ }^{4}$ A bibliografia sobre esse assunto está muito bem articulada no livro de Nádia Souki, intitulado Hannah Arendt e a banalidade do mal, publicado pela Editora da UFMG, em 1998. 
Em Origens, o tema aparece no cotejamento e no prolongamento da reflexão kantiana sobre o mal radical. Kant percebeu que o mal pode não ter origem nos instintos ou na natureza pecaminosa do homem e, sim, nas faculdades racionais que o fazem livre. Desse modo, o mal não possui dimensão ontológica, mas contingencial. Ele acontece a partir da interação e da reação das faculdades espirituais humanas às circunstâncias. O mal radical, em Kant, é uma espécie de rejeição consciente ao bem e está atrelado, ainda, ao uso dos homens como meios, instrumentos e não fim em si mesmos. Arendt retém esse aspecto da reflexão kantiana, acrescentando-lhe a dimensão históricopolítica do seu próprio tempo. Nessa abordagem, o radicalismo relaciona-se à novidade e ao assombro diante dos campos de concentração ${ }^{5}$. Isso faz o assunto ultrapassar a questão judaica, embora seja incompreensível sem ela. O holocausto é pouco para captar o que surgiu. O mal radical está associado a uma organização governamental e sistemática da vida dos homens, prescindindo do discurso e da ação, considerando-os meros animais, controláveis e descartáveis. Essa forma de governar sustenta-se no pressuposto do extermínio de setores da população e não apenas na sua opressão ou instrumentalização. Isso não diz respeito apenas à exclusão sociopolítica do criminoso, nem à eliminação do opositor ou do inimigo, mas à atualização da lógica da descartabilidade humana inerente àquela forma de governo.

Ao levar em conta a população apenas do ponto de vista biológico, laborante, o governo total tratou de eliminar qualquer instituição ou vínculo humano que pudesse dar abrigo à solidariedade, à ação e à diferenciação entre os indivíduos ${ }^{6}$. Destruindo o mundo comum, os espaços de aparição, no quais as pessoas poderiam ser amparadas e respeitadas, os governos totalitários constituíram-se baseados na propaganda, na espetacularização, na atomização, na solidão, na padronização, na coletivização das massas e na redução do homem a animal, ocupado exclusivamente com a sua reprodução biológica. Os regimes totais conceberam os homens apenas como seres vivos e prolongaram esse critério na escolha dos merecedores da vida. O grande temor, presente nos textos da pensadora, é que o extermínio, a nova terapia contra os humanos considerados impuros e indignos, inerente aos governos totalitários, viesse a constituir-se em elemento imanente aos governos e sociedades contemporâneas. Isso levou Arendt a afirmar: "[...] talvez os verdadeiros transes do nosso tempo somente venham a assumir a sua forma autêntica - embora não necessariamente a mais cruel - quando o totalitarismo pertencer ao passado" (ARENDT, 1990, p. 512).

\footnotetext{
${ }^{5}$ Sobre isso, é importante conferir o enfático artigo de CHAUMONT, J.-M. "La singularité de l'univers concentrationnaire selon Hannah Arendt". In: ROVIELLO, Anne-Marie; WEIYEMBERGH, M. (Org.). Hannah Arendt et la modernité. Paris: Vrin, 1992. p. 87-109.

${ }^{6}$ Sobre esse aspecto do pensamento de Arendt, merecem ser ressaltados os trabalhos de Macedo e Correia publicados em CORREIA, 2006, p. 147-162 e 255-236, respectivamente.
} 
A ligação entre o mal e a dominação retorna, em Arendt, quando ela aceita o convite de uma revista americana para fazer a cobertura do julgamento de Eichmann, ocorrido em Jerusalém em 1962 (cf. ARENDT, 2000a). Se, ao mal radical Arendt associa o surgimento e a prática da violência extremada e sistemática contra setores da população por parte de uma nova forma de governo, ao mal banal ela vai relacionar a prática dos agentes encarregados de executar as ordens governamentais. Quem foi Eichmann? Trata-se do principal responsável pelo envio dos judeus aos campos de concentração. Em todos os relatos de Arendt, verificamos uma profunda perplexidade com a maneira de Eichmann falar das suas atividades como carrasco nazista. Ele usava clichês, palavras de ordem e a moral da obrigação do bom funcionário para justificar o seu comportamento. Para ele, em nenhum momento, podia ser enquadrado como criminoso, pois apenas cumpria a sua obrigação, o seu dever. Eichmann era um ser humano normal, bom pai de família, não possuía nenhum ódio ao povo judeu e não era motivado por uma vontade de transgredir ou por qualquer outro tipo de maldade. No entanto, viabilizou o assassinato de milhões de pessoas. Foi justamente isso que levou Arendt a usar o termo banalidade do mal. Estamos diante de um tipo de mal sem relação com a maldade, a uma patologia ou a uma convicção ideológica. Estamos falando do mal como causa do mal, pois não tem outro fundamento. O praticante do mal banal não conhece a culpa. Ele age semelhante a uma engrenagem maquínica do mal. O mal banal parece ser um fungo, cresce e se espalha como causa de si mesmo, sem raiz alguma e atinge contingentes enormes das populações humanas, em diversos lugares da terra.

A pergunta de Arendt, ao se deparar com os depoimentos de Eichmann, foi: o que faz um ser humano normal realizar os crimes mais atrozes, como se não estivesse fazendo nada demais? A resposta está no mal banal. Uma prática do mal promissora, nas sociedades massificadas, possuidoras de organizações econômicas, políticas e sociais potentes, nas quais, os seres humanos tendem a se sentir sem poder, solitários, submissos e quase condicionados. Vivendo apenas como animais laborantes, os homens tecnificam e burocratizam as suas obrigações e se tornam, desse modo, incapazes de pensar as consequências das ordens dadas pelos seus superiores ou grupos. Eichmann, segundo Arendt, agiu igual ao cão de Pavlov, que foi condicionado a salivar mesmo sem ter fome. Ele não praticou o mal motivado pela ambição, ódio ou doença psíquica. Nada disso foi encontrado em Eichmann. A única coisa que chamou a atenção de Arendt foi a sua incapacidade de pensar. Ao renunciar ao pensamento, Eichmann destituiu-se da condição de ser dotado de espírito que lhe possibilitaria o descondicionamento e, assim, dizer: "não, isso eu não posso". 
O mal banal liga ausência de pensamento à dominação. Essa ausência provoca a privação da responsabilidade e pode explicar o apoio mudo das massas aos governos totalitários. O praticante do mal banal submete-se de tal forma a uma lógica externa que não enxerga a sua responsabilidade nos atos que pratica. Age como mera engrenagem. Não se interroga sobre o sentido da sua ação ou dos acontecimentos ao seu redor. Não mede nem busca a estatura do que está acontecendo a partir do crivo da dignificação dos envolvidos. Quem pensa resiste à prática do mal. A busca da significação encontra muita dificuldade quando a pressa, os mecanismos e procedimentos técnicos, burocráticos e os processos econômicos autopropelidos engolfam tudo. O praticante do mal banal renuncia à capacidade pertencente aos humanos de mudar o curso das ações rotineiras, através do exercício da iniciativa própria. Repete heteronomamente o seu comportamento. Não exercita a habilidade, peculiar aos homens, de falar e de comunicar o que está vendo e sentindo. Em suma, recusa-se a viver com os dons provenientes das suas faculdades espirituais: pensar, querer e julgar.

Tendo em vista essa situação, a autora propõe a recuperação da política como instância de fundação do mundo comum e de resistência à sua destruição. Ligar poder a mundo comum é compreendê-lo como condição para o florescimento dos homens e não como uma função da dominação ou a serviço do extermínio humano. Nessa empreita, encontramos elementos para pensarmos a categoria poder, principalmente em A Condição Humana (1958), mas, também, em O que é a Política (1950-1959), Da Revolução (1963), Crises da República (1969-1972), entre outras. Nessas obras, Arendt defende o cuidado com o mundo comum, o amor mundi, o respeito aos espaços onde os homens podem circular e se sentir amparados pela presença dos iguais e dos diferentes. As categorias que emergem nessa recuperação da política, em Arendt, são: condição humana, espaço público, liberdade, pluralidade, fundação, iniciativa, resistência, desobediência civil, participação e aparição. Podemos, então, nos interrogar: por que Arendt não associa poder político ao desenvolvimento das categorias Estado, Nação, Soberania, Democracia, Partidos, Estado de Direito, Direitos Humanos, que são as formas tipicamente modernas de expor e de refletir sobre o tema? ${ }^{7}$

Na verdade, tratou-se de uma estratégia deliberada de abordagem, cujo sentido era evitar a equiparação de poder a domínio, a força, a violência e a

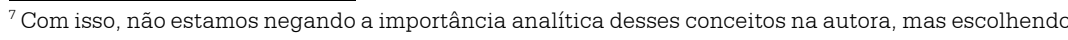
uma trilha para abordarmos o seu conceito de poder na qual eles são constitutivamente negativos. Habermas acha que, ao esquecer a dimensão estratégica inerente à visão moderna e ao buscar o sentido originário da política, Arendt enfraquece o seu conceito de poder (HABERMAS, 1993). Tratase, evidentemente, de uma incompreensão das motivações e objetivos da empreita compreensiva do pensamento de Arendt. Habermas não problematiza a dominação moderna com o mesmo parti pris arendtiano: o mal.
} 
governo. Em Arendt, poder relaciona-se à dimensão de legitimidade, autoridade, significação, potencia e constituição política. Para ela, o importante era a qualidade da organização da vida comum e não a mera eficácia dos aparelhos estatais. A medida dessa qualidade era a preservação da capacidade de iniciativa, de expressão e de aparição dos membros da comunidade. Mais importante do que a captura burocrático-natural das pessoas, nas malhas governamentais, era o mundo, a cultura, a vida comum que o poder é capaz de fundar. Vale dizer, em nenhum momento, Arendt ensejou discutir e propor modelos para os meandros do poder constituído, governamental, mas visou a resguardar a capacidade de ação em conjunto e de participação efetiva das pessoas na vida pública. Mais importante do que a determinação normativa ou jurídica dos governos e do Estado é, em Arendt, saber a base e a forma sobre a qual está assentado o apoio do povo ao poder constituído. Para Arendt, trata-se de fundar espaços em que o apoio e a constituição do poder não seja naturalizada e burocratizada. Evitar a forma administrativa, anônima, solitária, estatística e violenta, é o grande desafio que uma constituição genuinamente política tem de enfrentar. A ligação de base entre Estado-Nação-Soberania está na raiz da burocratização da representação política moderna. Ao vincular a pertença estatal ao nascimento, o Estado moderno abriu as portas para o racismo e a para a biologização da dinâmica e da sustentação do poder e deixou de lado a sua constituição política. O poder, assim, tornou-se sinônimo de força e de violência. No lugar do mundo comum, surge, pois, nessas circunstâncias, o deserto ${ }^{8}$.

Esse é o motivo pelo qual, em A Condição Humana, Arendt irá tentar diferenciar filológica e semanticamente trabalho (labor), obra ou fabricação (work) e ação ou práxis (action) ${ }^{9}$. O trabalho (labor) é a atividade através da qual o homem se reproduz enquanto mero ser vivo, membro da espécie animal humana. O fruto do trabalho (labor) não constitui um mundo, uma cultura, por isso, não gera nenhuma permanência. Essa atividade galgou a mais elevada hegemonia, a partir da modernidade. A obra ou fabricação é a atividade em que os homens constroem e produzem o mundo artificial: instrumentos, objetos, máquinas e as obras culturais. Nessa atividade, os homens se relacionam com a natureza como matéria-prima e meio para os seus projetos. Estamos discorrendo sobre o Homo Faber, o qual obteve algum prestígio no Renascimento, mas, na modernidade, suas atividades foram subsumidas pelo labor do animal laborans. Já a ação é a atividade na qual os homens se mostram capazes de agir, de falar e de entrar em contato uns

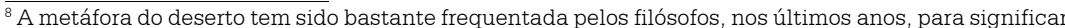
a problemática situação da política contemporânea. Ela foi inaugurada por Arendt, nos anos 1950, e é uma constante na obra O que é a Política (cf. ZIZEK, 2003).

${ }^{9}$ Sobre a tradução de labor, work e action por trabalho, fabricação e ação, cf. CALVET, 1985, p. 131-168. 
com os outros, bem como de constituir o mundo no seu habitat e lugar capaz de permitir a realização desses como seres falantes e agentes. Se o homem, no trabalho, age determinado pela necessidade de se manter vivo e, na fabricação, submete-se à silenciosa lógica da criação dos objetos, é na ação que ele reage, de modo singular, aos apelos provenientes das relações estabelecidas com os outros seres humanos. O sentido dessa diferenciação categorial é a recuperação do sentido do poder político que está perdido, na modernidade, nos meandros da administração, da policia, da estatística, da opinião pública anônima e dos demais aparelhos de Estado.

Em vários textos, Arendt diferencia poder (Macht) de domínio (Herschaft), autoridade de mando, política de administração, poder de governo. Com isso, enseja demarcar e resguardar a ideia de poder constituinte, poder esse que não pode ser confundido com poder constituído: governo e aparelhos governamentais ${ }^{10}$. Em todas as análises de Arendt sobre o tema do poder, observamos que ela se mantém firme na defesa da acepção do poder como essa dimensão capaz de possibilitar o surgimento dos homens como seres livres, e essa liberdade é entendida como capacidade de agir com os outros. Esse aspecto do seu pensamento a tornou conhecida como uma autora que renovou a Filosofia Política, na contemporaneidade. Ela colocou em circulação a retomada da categoria da ação para se pensar o poder. $O$ entrelaçamento entre poder, ação, condição humana e espaço público permite a focalização da visada arendtiana que privilegia a dimensão constituinte como mais importante do que a dimensão constituída, na sua reflexão sobre o poder.

Ao intitular de A Condição Humana a obra principal na qual aborda a ação, Arendt demarcou argumentativamente a sua temática. Em primeiro lugar, relacionou poder à fragilidade da existência humana, à mortalidade, evitando estribar o poder num conceito determinado da vida ou da natureza humana. Declara ela: "Para evitar erros de interpretação: a condição humana não é o mesmo que a natureza humana, e a soma total das atividades e capacidades humanas que correspondem à condição humana não constituem algo que se assemelhe à natureza humana" (ARENDT, 1983, p. 18). O poder liga-se tanto à indeterminação da existência humana, preço da liberdade, quanto ao limite da vida, na morte. A indeterminação da existência possibilita pensar o poder como potência, referido às possibilidades plurais de organização da vida em comum e de superar os modos estagnados de convivência. Poder e fundação, novo começo é a mesma coisa. Evita, assim, a autora, pensar a política a partir de fundamentos identitários, religiosos,

${ }^{10}$ A diferença entre poder constituinte e constituído foi proposta pela primeira vez por Emmanuel Joseph Sieyès, em Qu'est-ce que le tiers état?, de 1789, mas, segundo Agamben (2002, p. 48-50), a equiparação entre poder constituinte, poder soberano e nação, nesse autor, levou a uma concepção naturalizante do poder. 
naturalistas, coletivistas e qualifica a política como espaço de revelação, proteção, cultivo e realização das capacidades humana de agir e falar.

Quando Arendt menciona a categoria condição humana, está se referindo às condições da existência humana, tais como "a vida, a natalidade e a mortalidade, a mundaneidade, a pluralidade e o planeta Terra" (ARENDT, 1983, p. 19). Ao relacioná-las à política, indaga a respeito do que está em poder do homem realizar, o que ele pode ou não fazer, e aponta a vida com os outros e a habitação comum do planeta terra como limites da ação humana, pois "homens, e não o Homem, vivem na Terra e habitam o mundo" (ARENDT, 1983, p. 15). Essas condições, evidentemente, não fabricam o conteúdo, o homem: contudo, viabilizam ou obstruem o aparecimento do seu ser-próprio: sua humanidade. Nascer, existir, habitar a terra e suportar a inevitabilidade da morte são condições recriadas pelas atividades do trabalho, da fabricação, da ação e do pensamento. Por intermédio dessas últimas, as necessidades vitais são amenizadas e recuam no seu teor coercitivo; o mundo surge como lugar de proteção e a terra pode ser embelezada; e, assim, por meio da ação e do que ela funda, tudo se conjuga para a garantia da continuidade descontinua da história. Ao tentar fugir desses limites, o homem pode realizar o impossível ou inimaginável, mas ao preço de perder-se a si mesmo.

Arendt concebe o poder como convivência, ação em conjunto e, assim, supera a visão contemplativa que a deduz da teoria, forjada na solitude filosófica, bem como critica a ideia moderna da ação soberana ou do Estado como instância legítima das iniciativas públicas. A busca por uma fundamentação absoluta, externa às lutas políticas, na prática filosófica ocidental, de alguma forma conjugou-se à tendência a entender o poder como coisa para poucos, legitimado a partir de critérios externos à vida em comum. A ligação entre poder e vontade, na visão moderna da soberania, também foi amplamente criticada por Arendt. ${ }^{11}$ Nenhuma vontade tem condição de sustentar ou impor por si mesma, de maneira continuada, uma ação política, capaz de reunir várias perspectivas. O poder não é uma qualidade individual, mas de grupos. Sem o concerto, pode haver diretriz governamental, obrigação, mando e terror, mas não ação. A ação política fundamenta-se na liberdade do cidadão e não no seu controle. O apoio livre, articulado em palavras e iniciativas, é o que faz uma forma de governo genuinamente política. Nem a solidão do tirano nem a mudez coletivista são capazes de organizar e sustentar politicamente uma comunidade. Não existe poder numa relação senhor-escravo.

${ }^{11}$ Essa perspectiva está muito bem exposta no capítulo "O que é liberdade", in: ARENDT, 2000b, p. 188-220. 
Por essas razões, as observações de Arendt sobre o poder confluem para a noção de espaço público. Este não é um conceito formal, ligado a uma ideia abstrata do direito nem à organização jurídica do Estado e, muito menos, formado através dos meios impessoais de comunicação (BENHABIB, 1996, p. 200). A terminologia arendtiana mantém a proximidade com a dimensão geográfica justamente para apontar uma ideia de espaço agonal de entrada no mundo comum (in between). Isso significa que esse espaço não é natural, não está dado, mas é um "entre" que surge na medida em que há convivência, aparição, expressão, deliberação pública dos assuntos relacionados ao destino comum. Há, assim, participação ativa dos membros nos assuntos da comunidade. Esses componentes ou características do espaço público, segundo Arendt, funcionam como garantia de que o governo não é exercido a partir dos interesses privados e mudos da economia, do sangue ou da $\operatorname{cor}^{12}$.

Ao priorizar a ideia de espaço público na sua reflexão sobre o poder, Arendt evita confundir o poder político com a organização burocrática da população e, muito menos, com a organização econômica da sociedade através da prevalência do labor que é a faceta social do poder resumido a controle. Reduzido a isso, o poder põe-se a serviço da naturalização da vida humana, dos padrões e da violência (cf. ARENDT, 1983, p. 59-68).

Na nossa compreensão, a ideia de espaço público confronta-se diretamente com o decisionismo das teorias soberanas do poder. A aposta de Arendt vai na direção da deliberação pública dos assuntos comuns. É essa instância pública que dá a medida da autoridade de um governo e não uma dimensão misteriosa, excepcional do poder. Não há, na autora em pauta, uma esfera sagrada da política, mas um espaço público, comum, em vista à atualização da capacidade de agir e falar dos homens. Isso é o contrário da institucionalização da violência e do enrijecimento dos dispositivos de domínio como forma de manter e de reproduzir as condições de manutenção da dominação.

Essa concepção viabiliza, na autora, pensar a ideia de desobediência civil como imanente à sua concepção de poder. Nenhuma visão que reduz o poder à sua dimensão constituída, como a concepção soberana, até hoje, foi capaz de incluir a resistência e a desobediência como inerente à teoria do poder. Para Arendt, a desobediência civil inscreve-se agonicamente no espaço público. Resguardar isso, para ela, era mais importante do que elaborar padrões eficazes de ações governamentais.

${ }^{12}$ A cultura política brasileira está longe de uma prática articulada politicamente do poder. No nosso imaginário, o poder está atrelado à "casa", evidenciando o quanto os interesses privados prevalecem e transformam o poder em mando e, até recentemente, em mandonismo. O controle privado dos cargos, da informação e do judiciário, ainda hoje, são sintomas desse imaginário. Essa dimensão está abordada nas obras: Casa Grande e Senzala (FREIRE, 1998) e a Casa e a Rua (DAMATTA, 1997) 
A prática da desobediência civil nasceu no mundo moderno e contemporâneo. Henri Thoreau escreveu sob esse título, em 1849, nos Estados Unidos, um panfleto conclamando todos a se oporem à escravidão e à guerra americana contra o México e a não pagarem impostos. Escreve, nesse documento: "[...] a prisão é o único lugar num Estado escravo em que um homem livre pode viver com honra". Mais do que isso, vai à prefeitura e deposita um documento no qual diz estar se desvinculando de qualquer instituição à qual não tenha dado consentimento tácito (cf. THOREAU, 1999, p. 5).

Os filósofos que debatem esse tema, na atualidade, notadamente John Rawls (1999) e Norberto Bobbio (1986), tendem a concebê-lo na dimensão jurídico-contratual. Neles, a desobediência civil vem abordada no âmbito da teoria moderno-contratual da obrigação. Pertencente a um ordenamento jurídico, no qual se vota e é votado, o cidadão obriga-se a obedecer às leis e ao poder constituído. No entanto, em alguns setores, as leis podem se mostrar como não apropriadas, inoperantes ou insuficientes, justificando-se, assim, o instituto da desobediência civil. De modo particular, a condescendência é maior em se tratando de questões econômicas. Nesses casos, as greves e outras formas de desobediência são aceitas de maneira restrita, exclusivamente como forma de pressionar os governantes ou outras autoridades responsáveis a cumprirem os direitos sociais. Poderíamos chamar essa concepção de desobediência civil de econômico-jurídica. Aceita-se a existência de um arcabouço constitucional, fruto do contrato firmado entre o governo e a sociedade e que é portador da justiça mínima necessária para se manter a ordem e a paz social e, sob a vigência desse arcabouço, reservase, para melhorá-lo, um pequeníssimo espaço para a desobediência civil.

Arendt aborda explicitamente a relação entre esfera pública e desobediência civil, no texto "Desobediência Civil", escrito em 1969 e publicado no Brasil no livro Crises da República (cf. ARENDT, 1973, p. 4990). A pensadora compreende os movimentos de desobediência civil como movimentos de resistência ao naturalismo nas relações de dominação e à indiferença política das sociedades de massa. Esses movimentos apresentam-se como fundadores de mundo, pois, através das suas organizações, não colocam como centrais apenas a barganha econômica, mas a tentativa de instaurar relações novas, nas quais todos possam se sentir motivados a participar e a cuidar do destino comum.

Segundo a autora, a relação imanente entre desobediência civil e espaço público a diferencia radicalmente da desobediência criminosa. O criminoso transgride a lei em segredo e sempre em proveito próprio, particular. Sua ação não é pautada em questões relacionadas ao mundo comum, mas é guiada pelo autointeresse. Arendt diferencia, também, desobediência civil 
do objetor de consciência, instituto que a maioria dos autores coloca no mesmo patamar da desobediência civil. O objetor de consciência é aquele que transgride a lei por uma questão de foro íntimo; a objeção à lei, no caso, vem motivada por valores morais ou religiosos. O objetor desobriga-se a praticar determinadas exigências legais, porque estas se contrapõem às suas convicções pessoais.

A desobediência civil ultrapassa por completo a transgressão criminosa. O criminoso não quer provocar e iniciar novas relações entre os homens. Sua ação é clandestina e destruidora. Ao contrário, mesmo quando se contrapõe à maioria, a ação do desobediente civil brota de compromissos que visam à fundação ou à renovação da comunidade em novas bases e, por isso, o seu fortalecimento. A desobediência, assim entendida, jamais é individual. A violação aberta à lei, o fato do contestador civil tomar a lei em aberto desafio, demonstra que a perspectiva é, embora discordante, de fundação ou re-fundação e não da destruição da comunidade. A dimensão política da desobediência civil está relacionada à sua tendência a inovar e a começar a instaurar espaços de liberdade para agir. É isso que faz a autora chamar de "ilhas de liberdade" os momentos em que os ativistas da resistência francesa se reuniam e agiam.

A dimensão pública é, assim, fundamental para pensarmos a desobediência civil e sua relação com o conceito arendtiano de poder. A desobediência civil só se realiza em concerto e não individualmente, instaura espaços de associações entre os homens, realiza-se em espaços públicos e não clandestinamente. A desobediência civil é instauradora do espaço público e pauta-se na participação e não na passividade e indiferença dos cidadãos. Baseando-se na capacidade de agir e de prometer, a desobediência civil só se realiza em plenitude na medida em que os homens, apesar das dificuldades, não perderam a confiança e a capacidade de contatar uns com os outros em palavras, gestos e ações.

Dessa maneira, partindo da tentativa totalitária de governar relacionada ao princípio da manipulabilidade e extermínio dos homens, Arendt pensa o poder como capacidade de fundar e de resistir. Por isso, foram fundamentais e apareceram na compreensão arendtiana do poder as categorias condição humana, espaço público e desobediência civil. Essa concepção de poder "precede toda e qualquer constituição formal da esfera pública e as várias formas de governo" (ARENDT, 1983, p. 212). O poder, desse modo, "jamais perde inteiramente seu caráter de potencialidade [...]. O poder é sempre um potencial de poder, não uma entidade imutável, mensurável e confiável como a força. O poder passa a existir entre os homens quando eles agem juntos e desaparece no instante em que eles se dispersam. [...] O poder é essa potencialidade da convivência" (ARENDT, 1983, p. 212-213). Ao ligar poder 
a potência, à dynamis, Arendt quer apontar a possibilidade de dissolução dos mecanismos de controle e de novos usos da liberdade e ressaltar a não coincidência entre poder, estado e sociedade. Essa coincidência provoca a estagnação do Estado e do direito. O poder é potência, porque sua fonte originária é a ação. Ao invés de institucionalização da violência que enrijece os mecanismos de domínio como forma de manter e reproduzir as condições de manutenção da violência, o poder é a condição de possibilidade para o novo. Não é o contrato, a vida, o consenso, a soberania, o direito, nem mesmo os direitos humanos, mas a potência de liberdade proveniente da ação e da fala que dá legitimidade aos corpos políticos. Temos, então, em Arendt, a deposição da coincidência entre direito, Estado, governo e poder. Poder está relacionado ao uso livre do espaço público e não à sua normatização jurídica.

Arendt situa o poder, portanto, no âmbito da significação, do sentido, na esfera da linguagem e, por isso, não o confunde com a força e a violência. A mudez, a insensatez, o automatismo e o controle são características do terror, da tirania e da necessidade natural, ao passo que o poder é permeado pela legitimidade e pela significação. A aposta arendtiana na política é a aposta de que a capacidade de agir e falar podem se inserir na lógica da fundação de espaços para a liberdade e não da morte, pois, conforme a pensadora, "o homem foi feito para começar e não para morrer".

AGUIAR, O. A. The constitutive dimension of power in Hannah Arendt's thought.Trans/ Form/Ação, (Marília); v.34, n.1, 2011, p.115-130.

ABSTRACT: This article investigates Hannah Arendt's conception of Power. She addressed this issue against the backdrop of the notion that practices of extermination performed by totalitarian regimes were inherently tainted by evil. This account is focused on the constitutive dimension power in that it associates power to the capacity of originating and founding actions performed together. State, government and sovereignty are not particularly analyzed here because they are derivative dimensions of power and not constitutional ones. Hannah Arendt defended a clear distinction between power and domination. The most important terms present in this work are: common world, human condition, action, public sphere, civil disobedience and potency.

KEYWORDS: Hannah Arendt. Power. Action. Public Realm. Civil Disobedience.

Referências

AGAMBEN, Giorgio. Homo Sacer. Tradução de Henrique Burigo. Belo Horizonte: Ed. UFMG, 2002.

Estado de exceção. Tradução de Iraci Poleti. São Paulo: Boitempo, 2004. 
ARENDT, Hannah. Origens do totalitarismo. Tradução de Roberto Raposo. São Paulo: Companhia das Letras, 1990. Brasil, 1998

O que é política? Tradução de Reinaldo Guarany. Rio de Janeiro: Bertrand A condição humana. Tradução de Roberto Raposo. Rio de Janeiro: Forense, 1983

Eichmann em Jerusalém: um relato sobre a banalidade do mal. Tradução de José Rubens Siqueira. São Paulo: Companhia das Letras, 2000a.

Entre o passado e o futuro. Tradução Mauro Barbosa de Almeida. São Paulo: Perspectiva, 2000b. $\overline{\mathrm{UnB}, 1} 1990$

Da revolução. Tradução de Fernando Dídimo Vieira. São Paulo: ÁticaSobre a violência. Tradução de André Duarte. Rio de Janeiro: RelumeDumará, 1994. 1973.

Crises da república. Tradução de José Volkmann. São Paulo: Perspectiva,

A vida do espírito. Tradução de Antônio Abranches et al. Rio de Janeiro: Relume-Dumará, 1992.

A dignidade da política. Coletânea organizada e traduzida por Antônio Abranches et al. Rio de Janeiro: Relume-Dumará, 1993.

BENHABIB, Seyla. The reluctant modernism of Hannah Arendt. Londres: Sage, 1996.

BERNSTEIN, Richard J. Hannah Arendt and Jewish Question. Cambridge: MIT Press, 1996.

BOBBIO, Norberto. Desobediência civil. In: BOBBIO, N.; MATTEUCCI, N.; PASQUINO, G. Dicionário de ciência política. Tradução coordenada por João Ferreira. Brasília: UnB, 1986. p. 335-388.

CALVET, Theresa. A categoria trabalho (labor) em Hannah Arendt. Ensaio, São Paulo, n. 14, p. 131-168, 1985.

CHALIER, Catherine. Radicalité et banalité du Mal. In: ABENSOUR, Miguel (Ed.). Ontologie et politique. Paris: Tierce, 1989. p. 237-256.

CHAUMONT, J.-M. La singularité de l'univers concentrationaire selon Hannah Arendt. In: ROVIELLO, A.-M.; WEIYEMBERGH, M. (Org.). Hannah Arendt et la modernité. Paris: Vrin, 1992. p. 87-110.

CORREIA, Adriano. Hannah Arendt e condição humana. Salvador: Quarteto, 2006. 
DAMATTA, Roberto. A casa e a rua. São Paulo: Rocco, 1997.

DISC, Lisa. Hannah Arendt and the limits of philosophy. Ithaca: Cornel University Press, 1994.

FREIRE. Gilberto. Casa grande e senzala. Rio de Janeiro: Record, 1998.

HABERMAS, J. O conceito de poder em Hannah Arendt. In: FREITAG, Barbara; ROUANET, P. S. (Org.). Habermas - sociologia. Tradução de Barbara Freitag. São Paulo: Ática, 1993. p. 100-118.

JARDIM, Eduardo. A duas vozes. Rio de Janeiro: Civilização Brasileira, 2007.

MACEDO, André Duarte. O pensamento à sombra da ruptura. Rio de Janeiro: Paz e Terra, 2000.

RAWLS, John. The justification of civil disobedience. In: FREEMAN, Samuel (Org.). Rawls: Collected papers. Massachusetts: Harvard University Press, 1999. p. 176-189.

SOUKI, Nádia. Hannah Arendt e a banalidade do mal. Belo Horizonte: Ed. UFMG, 1998.

STANLEY, John L. Is totalitarianism a new phenomenon? Reflections on Hannah Arendt's origins of totalitarianism. In: HINCHMAN, Lewis; HINCHMAN, Sandra (Org.). Hannah Arendt critical essays. New York: State University of New York Press, 1994. p. 7- 40.

THOREAU, Henry David. A desobediência civil. Tradução de Sergio Karam. Porto Alegre: L \& PM, 1999.

ZIZEK, Slavoj. Bem-vindo ao deserto do real! Tradução de Paulo Cezar Castanheira. São Paulo: Boitempo, 2003. 
